\title{
Transient Boundary Layer Laminar Free Convective Flow of a Nanofluid Over a Vertical Cone/Plate
}

\author{
Vasu Buddakkagari · Manish Kumar
}

Published online: 30 January 2015

(C) Springer India Pvt. Ltd. 2015

\begin{abstract}
Two-dimensional transient hydrodynamic boundary layer flow of incompressible Newtonian nanofluid past a cone and plate with constant boundary conditions is investigated numerically. The Newtonian nanofluid model incorporates the effects of Brownian motion and thermophoresis. In order to solve the transformed unsteady, nonlinear coupled boundary layer equations numerically under the conditions, an implicit finite difference scheme of CrankNicolson type has been employed. Numerical results obtained for the velocity, temperature and nanoparticle concentration distributions, as well as the skin friction, local Nusselt number and local Sherwood number for several values of the parameters, namely the buoyancy ratio parameter, Prandtl number, Lewis number and nanofluid parameters. The dependency of the thermophysical properties has been discussed on these parameters. The results shown that the Brownian motion parameter increased, the local skin friction decreased while the local Nusselt number and local Sherwood number increased. However, they both decreased as the thermophoresis parameter increased. The approach used in optimizing the transient boundary layer heat transfer of nanofluid problems. The use of nanoparticles improve the heat transfer performance of the base fluids having poor thermophysical properties which are not able to meet the cooling rate of modern engineering equipments.
\end{abstract}

Keywords Brownian motion - Thermophoresis - Nanofluid · Lewis number · Nusselt number $\cdot$ Cone $\cdot$ Plate

\section{List of symbols}

$\begin{array}{ll}\mathrm{x}, \mathrm{y} & \text { Coordinates along the plate generator and normal to the generator respectively } \\ \mathrm{u}, \mathrm{v} & \text { Velocity components along the } \mathrm{x} \text { - and } \mathrm{y} \text { - directions respectively } \\ t^{\prime} & \text { Time } \\ \mathrm{t} & \text { Dimensionless time }\end{array}$

V. Buddakkagari $(\bowtie) \cdot$ M. Kumar

Department of Mathematics, Motilal Nehru National Institute of Technology, Allahabad, India

e-mail: bvsmaths@gmail.com 


$\begin{array}{ll}\mathrm{f} & \text { Nano-particle volume fraction } \\ G r & \text { Thermal Grashof number } \\ \mathrm{Nu}_{\mathrm{X}} & \text { Non-dimensional local Nusselt number } \\ \mathrm{Pr} & \text { Prandtl number } \\ T^{\prime} & \text { Temperature } \\ \mathrm{T} & \text { Dimensionless temperature } \\ D_{B} & \text { The Brownian diffusion coefficient } \\ D_{T} & \text { The thermophoresisdiffusion coefficient } \\ \mathrm{g} & \text { The acceleration due to gravity, } \\ \mathrm{Gr} & \text { Thermal Grashof number } \\ \mathrm{k} & \text { Thermal conductivity } \\ \mathrm{Le} & \text { Lewis number } \\ \mathrm{Nb} & \text { Brownian motion parameter } \\ \mathrm{Nr} & \text { Buoyancy ration number } \\ \mathrm{Nt} & \text { Thermophoresis parameter } \\ \mathrm{Pr} & \text { Prandtl number } \\ \mathrm{U}, \mathrm{V} & \text { Dimensionless velocity components along the X-and Y- directions respectively } \\ \mathrm{X}, \mathrm{Y} & \text { Dimensionless spatial coordinates along the plate generator and normal to the } \\ & \text { generator respectively } \\ \mathrm{Sc} & \text { Schmidt number } \\ \mathrm{Sh} & \text { Non-dimensional local Sherwood number }\end{array}$

\section{Greek symbols}

$\begin{array}{ll}\alpha & \text { Thermal diffusivity } \\ \rho_{f} & \text { The density of the base fluid } \\ \rho_{P} & \text { The density of the nanoparticles } \\ (\rho C)_{f} & \text { The heat capacity of the base fluid } \\ (\rho C)_{P} & \text { The effective heat capacity of the nanoparticles material } \\ \beta & \text { Volumetric thermal expansion coefficient } \\ \gamma & \text { The cone apex half angle } \\ \Phi & \text { Nano-particle volume fraction } \\ \mu & \text { Dynamic viscosity } \\ \nu & \text { Kinematic viscosity } \\ \Delta t & \text { Dimensionless time-step } \\ \Delta X & \text { Dimensionless finite difference grid size in X-direction } \\ \Delta Y & \text { Dimensionless finite difference grid size in Y-direction } \\ \tau_{X} & \text { Dimensionless local skin-friction }\end{array}$

\section{Subscripts}

$\begin{array}{ll}w & \text { Condition on the wall } \\ \infty & \text { Free stream condition }\end{array}$




\section{Introduction}

The idea of improving heat transfer performance of fluids with the inclusion of solid particles was first introduced by [1]. Suspensions involving mille or micro sized particles create problems, such as fast sedimentation, clogging of channels, high pressure drop, and severe erosion of system boundaries. To overcome these problems, [2] used ultrafine nanoparticles with base fluid known as nanofluid. Modern material technologies facilitated the manufacturing of nanometer-sized particles. A comprehensive survey of convective transport in nanofluids was made by [3], who considered seven slip mechanisms that can produce a relative velocity between the nanoparticles and the base fluid: inertia, Brownian diffusion, thermophoresis, diffusiophoresis, Magnus effect, fluid drainage, and gravity. Of all of these mechanisms, only Brownian diffusion and thermophoresis were found to be important. An analytic study on the onset of convection in a horizontal layer of a porous medium with the Brinkman model and the Darcy model filled with a nanofluid was presented by [4]. [5] presented the recent experimental and theoretical studies on convective heat transfer in nanofluids, their thermophysical properties and applications, and clarified the challenges and opportunities for future research. Chamkha et al. [6] analyzed Natural Convective Boundary Layer Flow over a Sphere Embedded in a Porous Medium Saturated with a Nanofluid. Bapuji et al. [7] studied the unsteady Laminar Free Convection Flow Past a Non-Isothermal Vertical Cone in the Presence of a Magnetic Field. Gorla et al. [8] studied the mixed Convection Flow of Non-Newtonian fluid from a Slotted Vertical Surface with Uniform Surface Heat Flux. Recently, Chamkha et al. [9] considered the unsteady free convective boundary layer flow of a nanofluid over a vertical cylinder. The model used for the nanofluid incorporates the effects of Brownian motion and thermophoresis. RamReddy et al. [10] considered the effect of Soret parameter on mixed convective flow along a vertical plate in a nanofluid under convective boundary condition. A clear picture about the nanofluid boundary layer flows is still to emerge. Very recently, A finite element analysis is performed the unsteady natural convection flow of a nanofluid past a vertical cone under the influence of applied magnetic field and thermal radiation by [11]. Motsa et al. [12] investigated the nonlinear density temperature variations in two-dimensional nanofluid flow over heated vertical surface with a sinusoidal wall temperature. On the other hand, the impetuous research on convective flow is surveyed in the recent books by Pop and Ingham [13], Incropera and Frank and Dewitt [14], Das et al. [15] and [16].

The objective of the present study is to analyze the unsteady, two-dimensional laminar free convective boundary-layer flow of a nanofluid over a permeable vertical cone or plate. The surface of the cone is maintained constant heat and nanoparticles volume fraction. The effects of nanoparticles Brownian motion and thermophoresis are included in the model.

In order to get a physical insight into the problems, the behaviour of the velocity, temperature, nanoparticles volume fraction, skin-friction, Nusselt number and Sherwood number are to discuss computationally for variations in the governing parameters.

\section{Mathematical Model}

We have considered the unsteady, laminar, two-dimensional natural convection boundary layer flow of a nanofluid over a vertical flat cone or plate. The cone is placed with its axis of symmetry along the vertical direction and the origin of the coordinate system and its vertex, $\mathrm{x}$-axis is measured along surface of the cone and $\mathrm{y}$-axis is measured perpendicular to the conical surface, as shown in the following Fig. 1. Here $\gamma$ is the cone apex half angle. Initially, the fluid and the cone are at the same temperature $T_{\infty}$ and the nanoparticles volume faction 

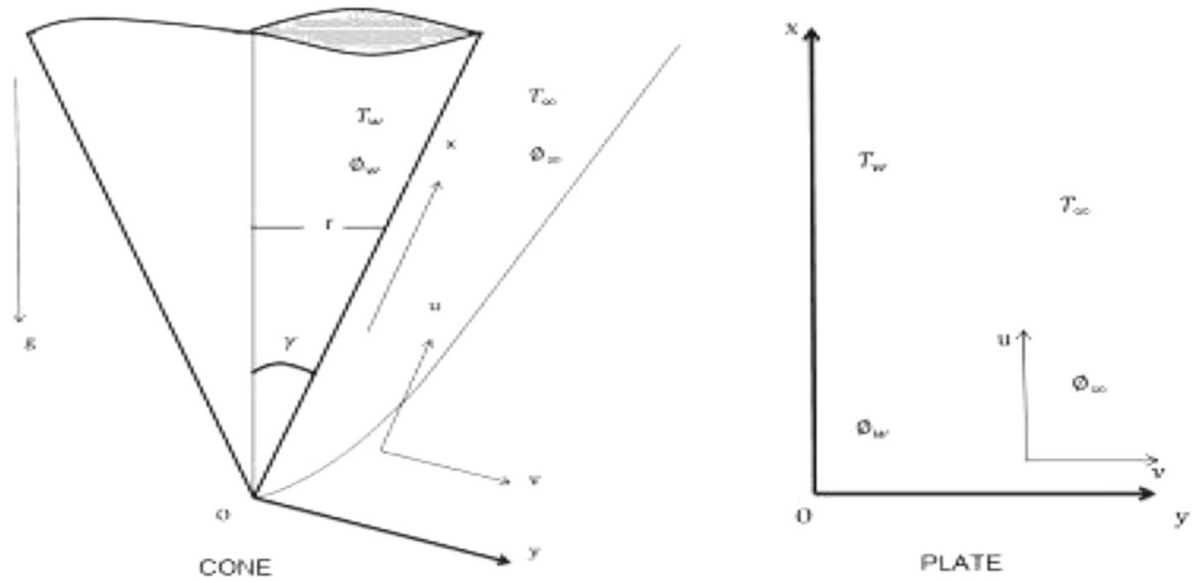

Fig. 1 Flow configuration coordinate system

$\varphi_{\infty}$. At time $t^{\prime}>0$, the temperature and the nanoparticles volume faction of the cone are raised to $T=T_{w}$, and $\varphi=\varphi_{w}$, respectively and are maintained constantly thereafter. It is also assumed that all the fluid properties are constant except that of the influence of the density variation with temperature and the nanoparticles volume faction in the body force term (Boussinesq's approximation).

In light of the above assumptions and under Boussinesq and boundary layer approximations, according to [3], [7], [17], [18], the governing equations for continuity, momentum, energy and continuity for nanoparticles in the absence of chemical reactions are:

\section{Governing Equations}

$$
\begin{gathered}
\nabla \cdot V=0 \\
\rho_{f}\left(\frac{\partial V}{\partial t^{\prime}}+V \cdot \nabla V\right)=\mu\left(\nabla^{2} V\right)-\nabla P \\
+\left[\varphi \rho_{P}+(1-\varphi)\left\{\rho_{f}\left(1-\beta\left(T^{\prime}-T_{\infty}^{\prime}\right)\right)\right\}\right] \cos \gamma \\
(\rho C)_{f}\left(\frac{\partial T^{\prime}}{\partial \tilde{t}}+V . \nabla T^{\prime}\right)=k\left(\nabla^{2} T^{\prime}\right)+(\rho C)_{P}\left[D_{B} \nabla \varphi \cdot \nabla \mathrm{T}^{\prime}+\left(\frac{D_{T}}{T_{\infty}}\right) \nabla T^{\prime} . \nabla T^{\prime}\right] \\
\frac{\partial \varphi}{\partial t^{\prime}}+V \cdot \nabla \varphi=D_{B} \nabla^{2} \varphi+\left(\frac{D_{T}}{T_{\infty}}\right) \nabla^{2} T^{\prime}
\end{gathered}
$$

Where $\mathrm{V}=(\mathrm{u}, \mathrm{v})$ is the fluid velocity vector, $\mathrm{T}$ is the fluid temperature, $\varphi$ is the nanoparticles volume faction, $\mathrm{t}^{\prime}$ is the time, $\mathrm{P}$ is the pressure, $\rho_{f}$ is the density of the base fluid and $\rho_{P}$ is the density of the nanoparticles. $D_{B}$ and $D_{T}$ are the Brownian diffusion coefficient and the thermophoresis diffusion coefficient, respectively, $\mathrm{g}$ is the acceleration due to gravity, $\mu$, $\mathrm{k}$ and $\beta$ are the dynamic viscosity, thermal conductivity and volumetric volume expansion coefficient of the fluid, respectively. $(\rho C)_{f}$ and $(\rho C)_{P}$ are the heat capacity of the base 
fluid and the effective heat capacity of the nanoparticles material, respectively. $T_{\infty}$ is the free stream temperature. By assuming that nanoparticles volume fraction is dilute (that is, no particle-particle interaction exists) and using a suitable choice for the reference pressure, Eq. (2) can be linearized and written as follows:

$$
\begin{aligned}
\rho_{f}\left(\frac{\partial V}{\partial t^{\prime}}+V . \nabla V\right)= & \mu\left(\nabla^{2} V\right)-\nabla \mathrm{P} \\
& +\left[\left(\rho_{P}-\rho_{f_{\infty}}\right)\left(\varphi-\varphi_{\infty}\right)+\left(1-\varphi_{\infty}\right) \rho_{f_{\infty}} \beta\left(\mathrm{T}^{\prime}-T_{\infty}^{\prime}\right)\right] g \cos \gamma
\end{aligned}
$$

\section{Dimensional Equations and Boundary Condition}

Using the standard boundary-layer approximation, based on a scale analysis, the governing equations can be written as;

$$
\begin{gathered}
\frac{\partial\left(r^{h} u\right)}{\partial x}+\frac{\partial\left(r^{h} u\right)}{\partial y}=0 \\
\rho_{f}\left(\frac{\partial u}{\partial t^{\prime}}+u \frac{\partial u}{\partial x}+v \frac{\partial u}{\partial y}\right)=\mu \frac{\partial^{2} u}{\partial y^{2}}+\left[\left(1-\varphi_{\infty}\right) \rho_{f_{\infty}} \beta g \cos \gamma\left(T^{\prime}-T_{\infty}^{\prime}\right)\right. \\
\left.-\left(\rho_{P}-\rho_{f_{\infty}}\right) g \cos \gamma\left(\varphi-\varphi_{\infty}\right)\right] \\
\frac{\partial T^{\prime}}{\partial t^{\prime}}+u \frac{\partial T^{\prime}}{\partial x}+v \frac{\partial T^{\prime}}{\partial y}=\alpha \frac{\partial^{2} T^{\prime}}{\partial y^{2}}+\tau\left[D_{B} \frac{\partial \varphi}{\partial y} \frac{\partial T^{\prime}}{\partial y}+\frac{D_{T}}{T_{\infty}^{\prime}}\left(\frac{\partial T^{\prime}}{\partial y}\right)^{2}\right] \\
\frac{\partial \emptyset}{\partial t^{\prime}}+u \frac{\partial \emptyset}{\partial x}+v \frac{\partial \emptyset}{\partial y}=D_{B} \frac{\partial^{2} \emptyset}{\partial y^{2}}+\left(\frac{D_{B}}{T_{\infty}^{\prime}}\right) \frac{\partial^{2} T^{\prime}}{\partial y^{2}}
\end{gathered}
$$

With $\mathrm{h}=0$ and $\gamma=0$ the above equations represent the convective transport from vertical plate; $\mathrm{h}=0$ and $\gamma \neq 0$, transport from wedge; $\mathrm{h}=1$ and $r=x \sin \gamma$ represents the convective transport from the vertical cone.

The initial and boundary conditions are:

$$
\begin{array}{ll}
t^{\prime}=0: \quad u=0, \quad v=0, \quad T^{\prime}=T_{\infty}^{\prime}, \quad \varphi=\varphi_{\infty} \quad \text { for all } x \text { and } y, \\
t^{\prime}>0: \quad u=0, \quad v=0, \quad T^{\prime}=T_{w}^{\prime}, \quad \varphi=\varphi_{w} \text { at } y=0 \\
u=0, \quad T^{\prime}=T_{\infty}^{\prime}, \quad \varphi=\varphi_{\infty} \text { at } x=0 \\
u \rightarrow 0, \quad T^{\prime} \rightarrow T_{\infty}^{\prime}, \quad \varphi \rightarrow \varphi_{\infty} \text { as } y \rightarrow \infty
\end{array}
$$

\section{Non-Dimensional Equations and Boundary Condition}

Using the following non-dimensional variables:

$$
\begin{aligned}
\mathrm{X} & =\frac{x}{\mathrm{~L}}, Y=\frac{y}{L}(G r)^{1 / 4}, \quad \mathrm{R}=\frac{r}{L}, \mathrm{U}=\frac{u \mathrm{~L}}{v}(G r)^{-1 / 2}, \quad V=\frac{\mathrm{L}}{v}(G r)^{-1 / 4} v, \\
\mathrm{t} & =\frac{v t^{\prime}}{\mathrm{L}^{2}}(G r)^{1 / 2} \quad T=\frac{T^{\prime}-T_{\infty}^{\prime}}{T_{w}^{\prime}-T_{\infty}^{\prime}}, \quad f=\frac{\varphi-\varphi_{\infty}}{\varphi_{w}-\varphi_{\infty}},
\end{aligned}
$$

The governing equations are reduced to the following dimensionless form:

$$
\frac{\partial}{\partial X}\left(R^{h} U\right)+\frac{\partial}{\partial R}\left(R^{h} V\right)=0
$$




$$
\begin{gathered}
\frac{\partial U}{\partial t}+U \frac{\partial U}{\partial X}+V \frac{\partial U}{\partial Y}=\frac{\partial^{2} U}{\partial Y^{2}}+\left[T-N_{r} f\right] \cos \gamma \\
\frac{\partial T}{\partial t}+U \frac{\partial T}{\partial X}+V \frac{\partial T}{\partial Y}=\frac{1}{P_{r}} \frac{\partial^{2} T}{\partial Y^{2}}+N_{b} \frac{\partial f}{\partial Y} \frac{\partial T}{\partial Y}+N_{t}\left(\frac{\partial T}{\partial Y}\right)^{2} \\
\frac{\partial f}{\partial t}+U \frac{\partial f}{\partial X}+V \frac{\partial f}{\partial Y}=\frac{1}{L_{e}}\left[\frac{\partial^{2} f}{\partial Y^{2}}+\frac{N_{t}}{N_{b}} \frac{\partial^{2} f}{\partial Y^{2}}\right]
\end{gathered}
$$

where

$$
\begin{aligned}
& \mathrm{Nb}=\frac{\tau D_{B}\left(\varphi_{w}-\varphi_{\infty}\right)}{v}, \quad N t=\frac{\tau D_{T}\left(T_{w}^{\prime}-T_{\infty}^{\prime}\right)}{v T_{\infty}^{\prime}}, \quad N r=\frac{\left(\rho_{P}-\rho_{f_{\infty}}\right)\left(\varphi_{w}-\varphi_{\infty}\right)}{\beta \rho_{f_{\infty}}\left(T_{w}^{\prime}-T_{\infty}^{\prime}\right)\left(1-\varphi_{\infty}\right)}, \\
& \operatorname{Pr}=\frac{\rho C_{P} v}{k}, \quad L e=\frac{v}{D_{B}}, \quad G r=\frac{g \beta\left(T_{w}^{\prime}-T_{\infty}^{\prime}\right)\left(1-\varphi_{\infty}\right) L^{3}}{v^{2}}
\end{aligned}
$$

are the Brownian motion parameter, thermophoresis parameter, buoyancy ratio parameter, Prandtl number, Lewis number and thermal Grashof number, respectively.

The dimensionless initial and boundary conditions become:

$$
\begin{array}{ll}
t=0: & U=0, \quad V=0, \quad T=0, \quad f=0 \quad \text { for all } X \text { and } Y, \\
t>0: & U=0, \quad V=0, \quad T=1, \quad f=1 \text { at } Y=0, \\
& U=0, \quad T=0, \quad f=0 \text { at } X=0, \\
& U \rightarrow 0, \quad T \rightarrow 0, \quad f \rightarrow 0 \text { as } Y \rightarrow \infty
\end{array}
$$

Of special significance for this type of flow and heat and mass transfer situation are the local skin-fraction coefficient $\tau_{X}$, the local rate of heat transfer or Nuselt number $N u_{x}$ and the local rate of mass transfer or Sherwood number $S h_{x}$. These physical quantities are defined in dimensionless form, respectively, as follows:

$$
\begin{gathered}
\tau_{X}=G r^{3 / 4}\left(\frac{\partial U}{\partial Y}\right)_{Y=0} \\
N u_{x}=-X G r^{1 / 4}\left(\frac{\partial T}{\partial Y}\right)_{Y=0} \\
S h_{x}=-X G r^{1 / 4}\left(\frac{\partial f}{\partial Y}\right)_{Y=0}
\end{gathered}
$$

\section{Numerical Solution}

In order to solve these unsteady, non-linear coupled Eqs. (12) to (15) under the conditions (16), an implicit finite difference scheme of Crank-Nicolson type has been employed [19]. This method has been extensively developed in recent years and remains one of the most reliable procedures for solving partial differential equation systems. It is unconditionally stable. It utilizes a central differencing procedure for space and is an implicit method. The partial differential terms are converted to difference equations and the resulting algebraic problem is solved using a tridiagonal matrix algorithm. For transient problems a trapezoidal rule is utilized and provides second-order convergence. The Crank-Nicolson Method (CNM) scheme has been used in numerous heat transfer, radiation and convection flow problems. The region of integration is considered as a rectangle with sides $X_{\max }(=1)$ and $Y_{\max }(=14)$, where $Y_{\max }$ corresponds to $Y=\infty$, which lies very well outside the momentum, energy and 
concentration boundary layers. The maximum of $\mathrm{Y}$ was chosen as 14 after some preliminary investigations, so that the last two of the boundary conditions (16) are satisfied within the tolerance limit $10^{-5}$.

The grid system is shown in the following Fig. 2.

The finite difference equations corresponding to Eqs. (12)-(15) are as follows:

$$
\begin{aligned}
& \frac{U_{i, j-1}^{n+1}-U_{i-1, j-1}^{n+1}+U_{i, j}^{n+1}-U_{i-1, j}^{n+1}+U_{i, j-1}^{n}-U_{i-1, j-1}^{n}+U_{i, j}^{n}-U_{i-1, j}^{n}}{4 \Delta x} \\
& +\frac{V_{i, j}^{n+1}-V_{i, j-1}^{n+1}+V_{i, j}^{n}-V_{i, j-1}^{n}+\frac{U_{i, j}^{n+1}+U_{i, j-1}^{n+1}+U_{i, j}^{n}+U_{i, j-1}^{n}}{2 \Delta y}=0}{2 i \Delta X} \\
& \frac{U_{i, j}^{n+1}-U_{i, j}^{n}}{\Delta t}+U_{i, j}^{n} \frac{U_{i, j}^{n+1}-U_{i-1, j}^{n+1}+U_{i, j}^{n}-U_{i-1, j}^{n}}{2 \Delta x} \\
& +V_{i, j}^{n} \frac{U_{i, j+1}^{n+1}-U_{i, j-1}^{n+1}+U_{i, j+1}^{n}-U_{i, j-1}^{n}}{4 \Delta y} \\
& =\frac{U_{i, j-1}^{n+1}-2 U_{i, j}^{n+1}+U_{i, j+1}^{n+1}+U_{i, j-1}^{n}-2 U_{i, j}^{n}+U_{i, j+1}^{n}}{2(\Delta y)^{2}} \\
& +\frac{T_{i, j}^{n+1}+T_{i, j}^{n}}{2} \cos \gamma-N r \frac{f_{i, j}^{n+1}+f_{i, j}^{n}}{2} \cos \gamma \\
& \frac{T_{i, j}^{n+1}-T_{i, j}^{n}+U_{i, j}^{n} \frac{T_{i, j}^{n+1}-T_{i-1, j}^{n+1}+T_{i, j}^{n}-T_{i-1, j}^{n}}{2 \Delta x}}{\Delta t} \\
& +V_{i, j}^{n} \frac{T_{i, j+1}^{n+1}-T_{i, j-1}^{n+1}+T_{i, j+1}^{n}-T_{i, j-1}^{n}}{4 \Delta y} \\
& =\frac{1}{\operatorname{Pr}} \frac{T_{i, j-1}^{n+1}-2 T_{i, j}^{n+1}+T_{i, j+1}^{n+1}+T_{i, j-1}^{n}-2 T_{i, j}^{n}+T_{i, j+1}^{n}}{2(\Delta y)^{2}}
\end{aligned}
$$

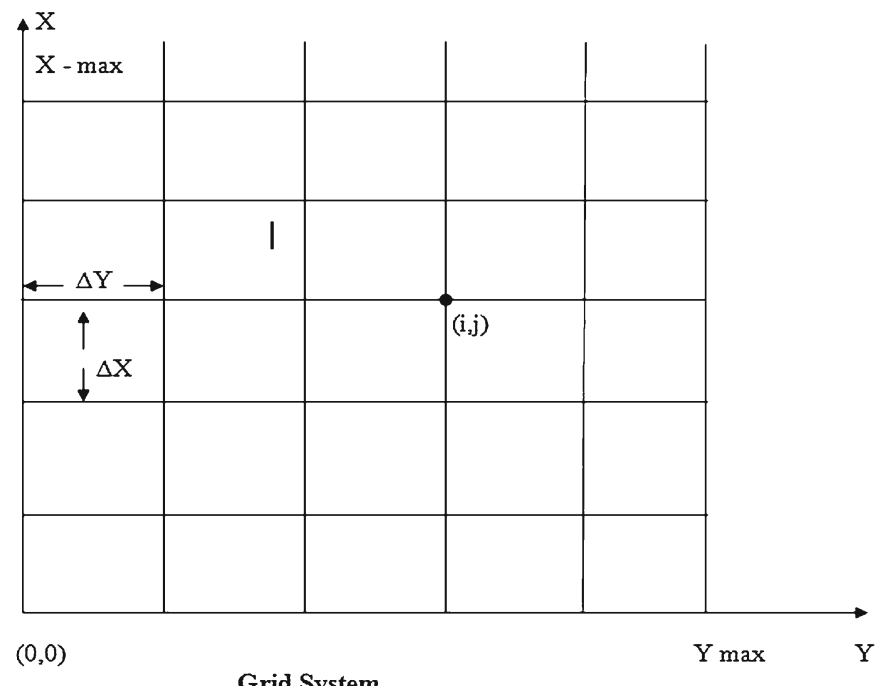

Fig. 2 Grid system representation 


$$
\begin{aligned}
& +N b \frac{\left(f_{i, j+1}^{n+1}-f_{i, j-1}^{n+1}+f_{i, j+1}^{n}-f_{i, j-1}^{n}\right)\left(T_{i, j+1}^{n+1}-T_{i, j-1}^{n+1}+T_{i, j+1}^{n}-T_{i, j-1}^{n}\right)}{16(\Delta y)^{2}} \\
& +N t \frac{T_{i, j+1}^{n}-T_{i, j-1}^{n} \frac{T_{i, j+1}^{n+1}-T_{i, j-1}^{n+1}}{2 \Delta y}}{2 \Delta y} \\
& \frac{f_{i, j}^{n+1}-f_{i, j}^{n}+U_{i, j}^{n} \frac{f_{i, j}^{n+1}-f_{i-1, j}^{n+1}+f_{i, j}^{n}-f_{i-1, j}^{n}}{2 \Delta x}}{\Delta t} \\
& +V_{i, j}^{n} \frac{f_{i, j+1}^{n+1}-f_{i, j-1}^{n+1}+f_{i, j+1}^{n}-f_{i, j-1}^{n}}{4 \Delta y} \\
& =\frac{1}{L e} \frac{f_{i, j-1}^{n+1}-2 f_{i, j}^{n+1}+f_{i, j+1}^{n+1}+f_{i, j-1}^{n}-2 f_{i, j}^{n}+f_{i, j+1}^{n}}{2(\Delta y)^{2}} \\
& +\frac{N t}{N b} \frac{T_{i, j-1}^{n+1}-2 T_{i, j}^{n+1}+T_{i, j+1}^{n+1}+T_{i, j-1}^{n}-2 T_{i, j}^{n}+T_{i, j+1}^{n}}{2(\Delta y)^{2}}
\end{aligned}
$$

Here, the subscript $i$-designates the grid point along the $\mathrm{X}$ - direction, $j$-along the $\mathrm{Y}$ direction and the superscript $n$ along the $t$-direction. An appropriate mesh size considered for the calculation is $\Delta X=0.05, \Delta Y=0.25$, and time step $\Delta t=0.01$. During any onetime step, the coefficients $U_{i, j}^{n}$ and $V_{i, j}^{n}$ appearing in the difference equations are treated as constants. The values of $U, V, T$ and $\mathrm{f}$ are known at all grid points at $t=0$ from the initial conditions. The computations of $U, V, T$ and $\mathrm{f}$ at time level $(n+1)$ using the known values at previous time level $(n)$ are calculated as follows.

The finite difference Eq. (23) at every internal nodal point on a particular $i$ - level constitute a tri-diagonal system of equations. Such a system of equations is solved by Thomas algorithm as described in [19]. Thus, the values of $f$ are found at every nodal point on a particular $i$ at $(n+1)$ th time level. Similarly, the values of $T$ are calculated from the Eq. (22). Using the values of $\mathrm{f}$ and $\mathrm{T}$ at $(n+1)$ th time level in the Eq. $(21)$, the values of $U$ at $(n+1)$ th time level are found in a similar manner. Thus the values of $f, T$ and $U$ are known on a particular $i$-level. The values of $V$ are calculated explicitly using the Eq. (20) at every nodal point on a particular $i$-level at $(n+1)$ th time level. This process is repeated for various $i$ - levels. Thus, the values of $f, T, U$ and $V$ are known at all grid points in the rectangular region at $(n+1)$ th time level. The detailed method of Crank-Nikolson type described in detail by [20].

Computations are carried out till the steady state is reached. The steady state solution is assumed to have been reached when the absolute difference between the values of the velocity $U$, as well as temperature $\theta$ and $f$ at two consecutive time steps are less than $10^{-5}$ at all grid points. The scheme is unconditionally stable. The local truncation error is $O\left(\Delta t^{2}+\Delta X^{2}+\right.$ $\Delta Y^{2}$ ) and it tends to zero as $\Delta t, \Delta X$ and $\Delta Y$ tend to zero. It follows that the CNM scheme is compatible. Stability and compatibility ensure the convergence.

The derivatives involved in Eqs. (17) to (19) are obtained using a five-point approximation formula and then the integrals are evaluated using the Newton-Cotes closed integration formula. The finite-difference scheme is unconditionally stable as explained by [21]. The stability and compatibility ensure the convergence.

\section{Result and Discussion}

This problem provides the behaviour of parameters involving in the expression of heat and mass transfer characteristics of the cone and plate. Numerical evaluation for this solution 
Table 1 Comparison of steady-state local skin friction and local Nusselt number values at $\mathrm{X}=0$ with those of [17] and [7] for full cone $(\mathrm{h}=1)$ when $\mathrm{n}=\mathrm{M}=0$, general fluid $\phi=0, \mathrm{Nb}=\mathrm{Nt}=0$

\begin{tabular}{|c|c|c|c|c|c|c|}
\hline \multirow[t]{3}{*}{ Pr } & \multicolumn{3}{|c|}{ Local skin friction } & \multicolumn{3}{|c|}{ Local Nusselt number } \\
\hline & {$[17]$} & [7] & Present values & [17] & [7] & Present values \\
\hline & $f^{\prime \prime}(\infty, 0)$ & $\tau_{X} / G r_{L}^{3 / 4}$ & $\tau_{X} / G r_{L}^{3 / 4}$ & $\theta^{\prime}(\infty, 0)$ & $N u_{x} / G r_{L}^{1 / 4}$ & $N u_{x} / G r_{L}^{1 / 4}$ \\
\hline 0.001 & 1.5135 & 1.4149 & 1.4137 & 0.0245 & 0.0294 & 0.0291 \\
\hline 0.01 & 1.3549 & 1.3356 & 1.3321 & 0.0751 & 0.0797 & 0.0781 \\
\hline 0.1 & 1.0962 & 1.0911 & 1.0899 & 0.2116 & 0.2115 & 0.2105 \\
\hline 1 & 0.7697 & 0.7668 & 0.7659 & 0.5111 & 0.5125 & 0.5113 \\
\hline 10 & 0.4877 & 0.4856 & 0.4851 & 1.0342 & 1.0356 & 1.0349 \\
\hline 100 & 0.2895 & 0.2879 & 0.2869 & 1.9230 & 1.9316 & 1.9311 \\
\hline 1000 & 0.1661 & 0.1637 & 0.1631 & 3.4700 & 3.5186 & 3.517 \\
\hline
\end{tabular}

Table 2 Effect of Lewis number $(L e)$ and various angle $\gamma$ on the Skin fraction number $\left(\tau_{X}\right)$, Nusselt number $\left(N u_{x}\right)$ and Sherwood number $\left(S h_{x}\right)$ at various $x$ over a cone

\begin{tabular}{|c|c|c|c|c|c|c|c|c|c|c|}
\hline \multirow[t]{2}{*}{$\gamma$} & \multirow[t]{2}{*}{ Le } & \multicolumn{3}{|l|}{$X=0$} & \multicolumn{3}{|c|}{$X=0.5$} & \multicolumn{3}{|c|}{$X=1.0$} \\
\hline & & $\tau_{X}$ & $N u_{x}$ & $S h_{x}$ & $\tau_{X}$ & $N u_{x}$ & $S h_{x}$ & $\tau_{X}$ & $N u_{x}$ & $S h_{x}$ \\
\hline \multirow[t]{3}{*}{0} & 1 & 0.5506 & 0.0680 & 0.0513 & 1.0655 & 0.3121 & 0.2171 & 1.2598 & 0.5344 & 0.3615 \\
\hline & 10 & 0.5614 & 0.0695 & 0.1064 & 1.0813 & 0.3250 & 0.3206 & 1.2772 & 0.5582 & 0.5154 \\
\hline & 100 & 0.5713 & 0.0699 & 0.2357 & 1.0862 & 0.3309 & 0.0531 & 1.2767 & 0.5669 & -1.1997 \\
\hline \multirow[t]{3}{*}{$30^{\circ}$} & 1 & 0.4938 & 0.0655 & 0.0493 & 0.9558 & 0.3019 & 0.2088 & 1.1301 & 0.5170 & 0.3474 \\
\hline & 10 & 0.5032 & 0.0671 & 0.1006 & 0.9698 & 0.3146 & 0.3065 & 1.1453 & 0.5404 & 0.4901 \\
\hline & 100 & 0.5117 & 0.0674 & 0.2234 & 0.9729 & 0.3204 & -0.1476 & 1.1443 & 0.5477 & -1.2532 \\
\hline \multirow[t]{3}{*}{$75^{\circ}$} & 1 & 0.1984 & 0.0485 & 0.0358 & 0.3842 & 0.2287 & 0.1496 & 0.4543 & 0.3927 & 0.2474 \\
\hline & 10 & 0.2016 & 0.04992 & 0.0636 & 0.3890 & 0.2398 & 0.2003 & 0.4589 & 0.4132 & 0.3018 \\
\hline & 100 & 0.2034 & 0.0504 & 0.1035 & 0.3887 & 0.2406 & -0.3457 & 0.4587 & 0.4110 & 0.2281 \\
\hline
\end{tabular}

of the problem is performed and the results are graphically illustrated. Computations were carried out for various values of parameters such as the buoyancy parameter $\mathrm{Nr}$, Brownian motion parameter $\mathrm{Nb}$, Thermophoresis parameter $N t$, Prandtl number $\mathrm{Pr}$ and Lewis number Le.

In order to provide evidence of the accuracy of our numerical results, the present results in steady state at $X=1.0$ are compared with existing solutions in the literature for the general fluid i.e there is no nanoparticle suspension $\phi=0$, only contains base fluid. In this case the continuity equation of nanoparticle become vanishes, it results the governing equations 1-3 only. The numerical values of the skin friction $\tau_{X}$ and local Nusselt number $\mathrm{Nu}_{\mathrm{x}}$ for different values of Prandtl number $\operatorname{Pr}$ with $M=n=0$ are compared with the results of [17] and [7] in Table 1 , where $f^{\prime \prime}(\infty, 0)$ and $\theta^{\prime}(\infty, 0)$ are the steady state local skin friction and the local Nusselt number for a full cone obtained by [17]. It is observed that the results are excellent agreement with each other.

Tables 2, 3 representing the effect of Angle $\gamma$ and Lewis Number Le on the Skin fraction number $\left(\tau_{X}\right)$, Nusselt number $\left(N u_{x}\right)$ and Sherwood number $\left(S h_{x}\right)$ at various point along 
Table 3 Effect of Lewis number $(L e)$ and various angle $\gamma$ on the Skin fraction number $\left(\tau_{X}\right)$, Nusselt number $\left(N u_{x}\right)$ and Sherwood number $\left(S h_{x}\right)$ at various $\mathrm{x}$ over a plate

\begin{tabular}{|c|c|c|c|c|c|c|c|c|c|c|}
\hline \multirow[t]{2}{*}{$\gamma$} & \multirow[t]{2}{*}{$L e$} & \multicolumn{3}{|l|}{$X=0$} & \multicolumn{3}{|l|}{$X=0.5$} & \multicolumn{3}{|c|}{$X=1.0$} \\
\hline & & $\tau_{X}$ & $N u_{x}$ & $S h_{x}$ & $\tau_{X}$ & $N u_{x}$ & $S h_{x}$ & $\tau_{X}$ & $N u_{x}$ & $S h_{x}$ \\
\hline \multirow[t]{3}{*}{0} & 1 & 0.5713 & 0.0660 & 0.0496 & 1.1964 & 0.2612 & 0.1761 & 1.4385 & 0.4378 & 0.2851 \\
\hline & 10 & 0.5818 & 0.0675 & 0.1005 & 1.2118 & 0.2732 & 0.2570 & 1.4549 & 0.4600 & 0.3894 \\
\hline & 100 & 0.5901 & 0.0679 & 0.1980 & 1.2158 & 0.2781 & -0.1492 & 1.4556 & 0.4647 & -0.7537 \\
\hline \multirow[t]{3}{*}{$30^{\circ}$} & 1 & 0.5127 & 0.0636 & 0.0478 & 1.0732 & 0.2526 & 0.1693 & 1.2903 & 0.4236 & 0.2737 \\
\hline & 10 & 0.5219 & 0.0651 & 0.0953 & 1.0867 & 0.2645 & 0.2445 & 1.3046 & 0.4455 & 0.3677 \\
\hline & 100 & 0.5290 & 0.0655 & 0.1873 & 1.0894 & 0.2690 & -0.2491 & 1.3048 & 0.4489 & -0.6840 \\
\hline \multirow[t]{3}{*}{$75^{\circ}$} & 1 & 0.2064 & 0.0469 & 0.0346 & 0.4313 & 0.1917 & 0.1206 & 0.5182 & 0.3224 & 0.1932 \\
\hline & 10 & 0.2096 & 0.0483 & 0.0612 & 0.4356 & 0.2021 & 0.1523 & 0.5224 & 0.3415 & 0.2141 \\
\hline & 100 & 0.2112 & 0.0488 & 0.0878 & 0.4356 & 0.2021 & -0.0938 & 0.5220 & 0.3414 & 0.2518 \\
\hline
\end{tabular}

Table 4 Effect of Prandtl number $(\mathrm{Pr})$ and Brownian motion $(\mathrm{Nb})$ on the Skin fraction number $\left(\tau_{X}\right)$, Nusselt number $\left(N u_{x}\right)$ and Sherwood number $\left(S h_{x}\right)$ at various $\mathrm{x}$ over a cone

\begin{tabular}{|c|c|c|c|c|c|c|c|c|c|c|}
\hline \multirow[t]{2}{*}{$\operatorname{Pr}$} & \multirow[t]{2}{*}{$\mathrm{Nb}$} & \multicolumn{3}{|l|}{$X=0$} & \multicolumn{3}{|c|}{$X=0.5$} & \multicolumn{3}{|l|}{$X=1.0$} \\
\hline & & $\tau_{X}$ & $N u_{x}$ & $S h_{x}$ & $\tau_{X}$ & $N u_{x}$ & $S h_{x}$ & $\tau_{X}$ & $N u_{x}$ & $S h_{x}$ \\
\hline \multirow[t]{3}{*}{0.71} & 0.1 & 0.5468 & 0.0689 & 0.1049 & 1.0533 & 0.3225 & 0.3172 & 1.2441 & 0.5539 & 0.5092 \\
\hline & 0.5 & 0.5447 & 0.0827 & 0.1920 & 1.0140 & 0.4775 & 0.5164 & 1.1828 & 0.8556 & 0.8552 \\
\hline & 1.0 & 0.5268 & 0.0974 & 0.2000 & 0.9504 & 0.6303 & 0.5501 & 1.0947 & 1.1466 & 0.9080 \\
\hline \multirow[t]{3}{*}{2.0} & 0.1 & 0.4342 & 0.0882 & -0.0164 & 0.8444 & 0.3879 & 0.1316 & 0.9961 & 0.6618 & 0.1381 \\
\hline & 0.5 & 0.4342 & 0.1128 & 0.1222 & 0.7849 & 0.64003 & 0.25277 & 0.90330 & 1.12793 & 0.38362 \\
\hline & 1.0 & 0.4097 & 0.1354 & 0.1384 & 0.7029 & 0.8492 & 0.2992 & 0.7947 & 1.5071 & 0.4489 \\
\hline \multirow[t]{3}{*}{7.0} & 0.1 & 0.3338 & 0.0875 & -0.0451 & 0.6983 & 0.3825 & -0.0270 & 0.8353 & 0.6637 & -0.5102 \\
\hline & 0.5 & 0.3326 & 0.1361 & 0.0535 & 0.6123 & 0.6463 & 0.1698 & 0.7059 & 1.1125 & 0.2277 \\
\hline & 1.0 & 0.3040 & 0.1686 & 0.0746 & 0.5242 & 0.8927 & 0.1229 & 0.5959 & 1.4852 & 0.1891 \\
\hline
\end{tabular}

Table 5 Effect of Prandtl number $(\mathrm{Pr})$ and Brownian motion $(\mathrm{Nb})$ on the Skin fraction number $\left(\tau_{X}\right)$, Nusselt number $\left(N u_{x}\right)$ and Sherwood number $\left(S h_{x}\right)$ at various $\mathrm{x}$ over a plate

\begin{tabular}{|c|c|c|c|c|c|c|c|c|c|c|}
\hline \multirow[t]{2}{*}{$\mathrm{Pr}$} & \multirow[t]{2}{*}{$\mathrm{Nb}$} & \multicolumn{3}{|l|}{$X=0$} & \multicolumn{3}{|c|}{$X=0.5$} & \multicolumn{3}{|c|}{$X=1.0$} \\
\hline & & $\tau_{X}$ & $N u_{x}$ & $S h_{x}$ & $\tau_{X}$ & $N u_{x}$ & $S h_{x}$ & $\tau_{X}$ & $N u_{x}$ & $S h_{x}$ \\
\hline \multirow[t]{3}{*}{0.71} & 0.1 & 0.5818 & 0.06753 & 0.1005 & 1.2118 & 0.2732 & 0.2570 & 1.4549 & 0.4600 & 0.3894 \\
\hline & 0.5 & 0.5785 & 0.0812 & 0.1825 & 1.1582 & 0.4242 & 0.4325 & 1.3695 & 0.7525 & 0.6714 \\
\hline & 1.0 & 0.5589 & 0.0957 & 0.1903 & 1.0784 & 0.5710 & 0.4592 & 1.2565 & 1.0277 & 0.7106 \\
\hline \multirow[t]{3}{*}{2.0} & 0.1 & 0.4654 & 0.0872 & -0.0178 & 0.9886 & 0.3296 & 0.0718 & 1.1886 & 0.5480 & 0.0720 \\
\hline & 0.5 & 0.4638 & 0.1116 & 0.1189 & 0.9069 & 0.5682 & 0.1970 & 1.0583 & 0.9814 & 0.2694 \\
\hline & 1.0 & 0.4369 & 0.1337 & 0.1348 & 0.8044 & 0.7629 & 0.2324 & 0.9202 & 1.3216 & 0.3155 \\
\hline \multirow[t]{3}{*}{7.0} & 0.1 & 0.3556 & 0.0896 & -0.0728 & 0.8306 & 0.3332 & -0.3330 & 1.0258 & 0.4846 & 0.0133 \\
\hline & 0.5 & 0.3544 & 0.1370 & 0.0500 & 0.7146 & 0.5665 & 0.1175 & 0.8405 & 0.9538 & 0.1253 \\
\hline & 1.0 & 0.3232 & 0.1683 & 0.0729 & 0.6069 & 0.7671 & 0.0937 & 0.7041 & 1.2355 & 0.1293 \\
\hline
\end{tabular}


Table 6 Effect of Lewis number $(L e)$ and Thermophoresis parameter $(N t)$ on the Skin fraction number $\left(\tau_{X}\right)$, Nusselt number $\left(N u_{x}\right)$ and Sherwood number $\left(S h_{x}\right)$ at various $\mathrm{x}$ over a cone

\begin{tabular}{|c|c|c|c|c|c|c|c|c|c|c|}
\hline \multirow[t]{2}{*}{ Le } & \multirow[t]{2}{*}{$N t$} & \multicolumn{3}{|l|}{$X=0$} & \multicolumn{3}{|c|}{$X=0.5$} & \multicolumn{3}{|c|}{$X=1.0$} \\
\hline & & $\tau_{X}$ & $N u_{x}$ & $S h_{x}$ & $\tau_{X}$ & $N u_{x}$ & $S h_{x}$ & $\tau_{X}$ & $N u_{x}$ & $S h_{x}$ \\
\hline \multirow[t]{3}{*}{1} & 0.1 & 0.5364 & 0.0674 & 0.0508 & 1.0380 & 0.3096 & 0.2151 & 1.2273 & 0.5302 & 0.3581 \\
\hline & 0.5 & 0.5244 & 0.0562 & -0.0308 & 1.0226 & 0.2357 & -0.1097 & 1.2126 & 0.3960 & -0.1711 \\
\hline & 0.7 & 0.5184 & 0.0506 & -0.0614 & 1.0192 & 0.2020 & -0.1780 & 1.2121 & 0.3374 & -0.2579 \\
\hline \multirow[t]{3}{*}{10} & 0.1 & 0.5468 & 0.0689 & 0.1049 & 1.0533 & 0.3225 & 0.3172 & 1.2441 & 0.5539 & 0.5092 \\
\hline & 0.5 & 0.5155 & 0.0544 & -0.0258 & 1.0194 & 0.2332 & 0.1685 & 1.2119 & 0.3903 & 0.0894 \\
\hline & 1.0 & 0.5190 & 0.0424 & 0.1682 & 1.0481 & 0.1634 & -0.0666 & 1.2643 & 0.2686 & 0.6020 \\
\hline \multirow[t]{3}{*}{100} & 0.1 & 0.5563 & 0.0693 & 0.2328 & 1.0577 & 0.3283 & 0.0021 & 1.2435 & 0.5622 & -1.2209 \\
\hline & 0.5 & 0.5228 & 0.0527 & 0.2505 & 1.0344 & 0.2869 & -4.5162 & 1.1708 & 0.3580 & -9.1746 \\
\hline & 1.0 & 0.6057 & 0.0419 & 1.5932 & 1.1257 & 0.1077 & & 1.2150 & 0.3672 & \\
\hline
\end{tabular}

Table 7 Effect of Lewis number $(L e)$ and Thermophoresis parameter $(N t)$ on the Skin fraction number $\left(\tau_{X}\right)$, Nusselt number $\left(N u_{x}\right)$ and Sherwood number $\left(S h_{x}\right)$ at various $\mathrm{x}$ over a plate

\begin{tabular}{|c|c|c|c|c|c|c|c|c|c|c|}
\hline \multirow[t]{2}{*}{ Le } & \multirow[t]{2}{*}{$N t$} & \multicolumn{3}{|l|}{$X=0$} & \multicolumn{3}{|c|}{$X=0.5$} & \multicolumn{3}{|c|}{$X=1.0$} \\
\hline & & $\tau_{X}$ & $N u_{x}$ & $S h_{x}$ & $\tau_{X}$ & $N u_{x}$ & $S h_{x}$ & $\tau_{X}$ & $N u_{x}$ & $S h_{x}$ \\
\hline \multirow[t]{3}{*}{1} & 0.1 & 0.5713 & 0.0660 & 0.0496 & 1.1964 & 0.2612 & 0.1761 & 1.4385 & 0.4378 & 0.2851 \\
\hline & 0.5 & 0.5591 & 0.0554 & -0.0308 & 1.1854 & 0.1946 & -0.0962 & 1.4314 & 0.3188 & -0.1373 \\
\hline & 0.7 & 0.5527 & 0.0499 & -0.0625 & 1.1852 & 0.1645 & -0.1481 & 1.4363 & 0.2687 & -0.1902 \\
\hline \multirow[t]{3}{*}{10} & 0.1 & 0.5818 & 0.0675 & 0.1005 & 1.2118 & 0.2732 & 0.2570 & 1.4549 & 0.4600 & 0.3894 \\
\hline & 0.5 & 0.5480 & 0.0537 & -0.0490 & 1.1803 & 0.1913 & 0.0567 & 1.4316 & 0.3104 & 0.1151 \\
\hline & 1.0 & 0.5457 & 0.0423 & 0.0611 & 1.2239 & 0.1262 & 0.2040 & 1.5026 & 0.2053 & 0.2194 \\
\hline \multirow[t]{3}{*}{100} & 0.1 & 0.5901 & 0.0679 & 0.1980 & 1.2158 & 0.2781 & -0.1492 & 1.4556 & 0.4647 & -0.7537 \\
\hline & 0.5 & 0.5542 & 0.0522 & 0.1757 & 1.1694 & 0.2128 & -5.2112 & 1.4515 & 0.2681 & 6.8882 \\
\hline & 1.0 & 0.5787 & 0.0431 & 0.4953 & 1.2666 & 0.1316 & 4.7410 & 1.5057 & 0.1739 & 1.6012 \\
\hline
\end{tabular}

Table 8 Effect of buoyancy ratio parameter $(N r)$ and various angle $\gamma$ on the Skin fraction number $\left(\tau_{X}\right)$, Nusselt number $\left(N u_{x}\right)$ and Sherwood number $\left(S h_{x}\right)$ at various $\mathrm{x}$ over a cone

\begin{tabular}{|c|c|c|c|c|c|c|c|c|c|c|}
\hline \multirow[t]{2}{*}{$\gamma$} & \multirow[t]{2}{*}{$\mathrm{Nr}$} & \multicolumn{3}{|l|}{$X=0$} & \multicolumn{3}{|c|}{$X=0.5$} & \multicolumn{3}{|c|}{$X=1.0$} \\
\hline & & $\tau_{X}$ & $N u_{x}$ & $S h_{x}$ & $\tau_{X}$ & $N u_{x}$ & $S h_{x}$ & $\tau_{X}$ & $N u_{x}$ & $S h_{x}$ \\
\hline \multirow[t]{3}{*}{0} & 0.1 & 0.5614 & 0.0695 & 0.1064 & 1.0813 & 0.3250 & 0.3206 & 1.2772 & 0.5582 & 0.5154 \\
\hline & 0.5 & 0.3886 & 0.0623 & 0.0895 & 0.7295 & 0.2930 & 0.2761 & 0.8552 & 0.5023 & 0.4335 \\
\hline & 1.0 & 0.1019 & 0.0454 & 0.0532 & 0.1016 & 0.1982 & 0.1334 & 0.0856 & 0.3353 & 0.1901 \\
\hline \multirow[t]{3}{*}{$30^{\circ}$} & 0.1 & 0.5032 & 0.0671 & 0.1006 & 0.9698 & 0.3146 & 0.3065 & 1.1453 & 0.5404 & 0.4901 \\
\hline & 0.5 & 0.3475 & 0.0601 & 0.0846 & 0.6533 & 0.2835 & 0.2628 & 0.7654 & 0.4861 & 0.4095 \\
\hline & 1.0 & 0.0895 & 0.0437 & 0.0502 & 0.0843 & 0.1906 & 0.1232 & 0.0725 & 0.3253 & 0.1789 \\
\hline \multirow[t]{3}{*}{$75^{\circ}$} & 0.1 & 0.2016 & 0.0499 & 0.0636 & 0.3890 & 0.2398 & 0.2003 & 0.4589 & 0.4132 & 0.3018 \\
\hline & 0.5 & 0.1373 & 0.0447 & 0.0537 & 0.2577 & 0.2154 & 0.1631 & 0.3005 & 0.3703 & 0.2380 \\
\hline & 1.0 & 0.0286 & 0.0315 & 0.0300 & 0.0217 & 0.1445 & 0.0727 & 0.0234 & 0.2526 & 0.1187 \\
\hline
\end{tabular}


Fig. 3 Steady state nanoparticle concentration profiles at $\mathrm{X}=1.0$ for different $\mathrm{Nb}$ over cone and plate

Fig. 4 Steady state velocty profiles at $\mathrm{X}=1.0$ for different $\mathrm{Nb}$ over cone and plate
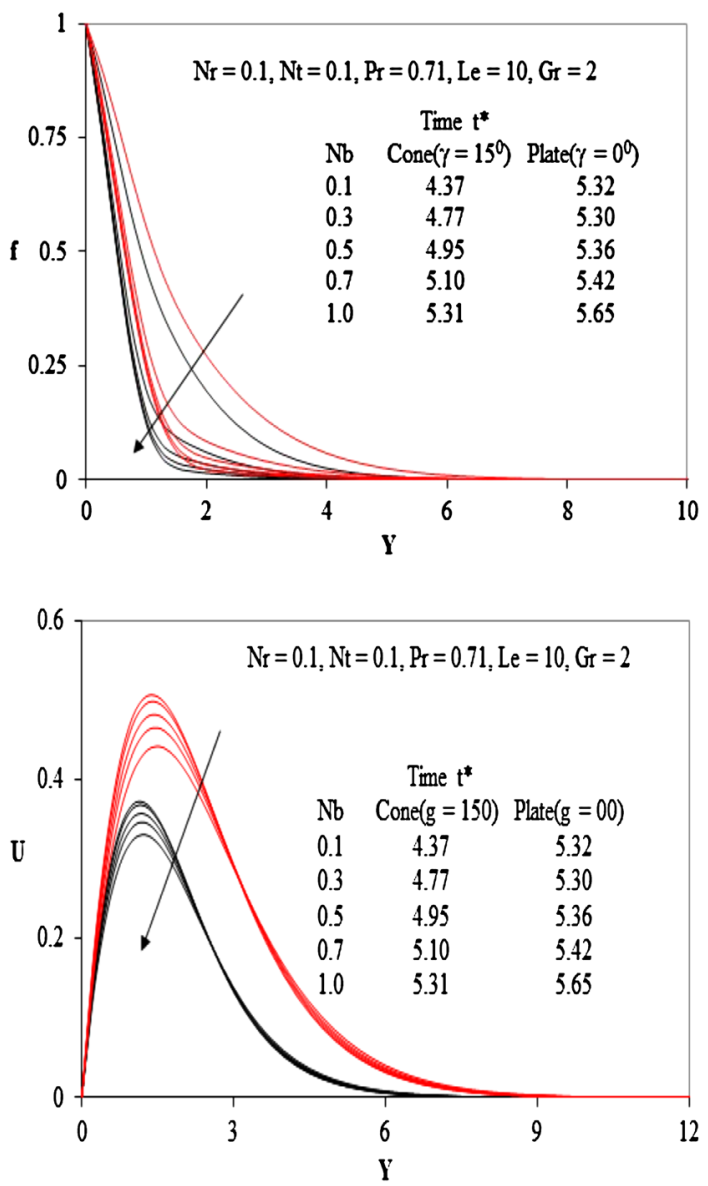

the surface $\mathrm{x}(0,0.5,1.0)$ for Cone, Plate respectively. $\tau_{X}$, Increased over the surface (i.e. $\mathrm{x}=0,0.5,1.0)$, also $\tau_{X}$ increased when $L e$ is increases and decreased when angle $\gamma$ is increases. Both $N u_{x}$ and $S h_{x}$ are increased along the surface (i.e. $\mathrm{x}=0,0.5,1.0$ ). Also observed that Nusselt and Sherwood number results are increased when $L e$ is increase and decreased when angle $\gamma$ is increase.

Tables 4, 5 representing the effect of Prandtl number $(\mathrm{Pr})$ and Brownian motion $\mathrm{Nb}$ on $\left(\tau_{X}\right),\left(N u_{x}\right)$ and $\left(S h_{x}\right)$ at various point along the surface $\mathrm{x}(0,0.5,1.0)$ for the Cone and Plate. $\left(\tau_{X}\right),\left(N u_{x}\right)$ and $\left(S h_{x}\right)$ are increased at various points along the cone and plate surfaces $\mathrm{x}=0,0.5,1.0$, also decreased when Prandtl number $(P r)$ and Brownian motion $N b$ increases. It is noticed that $\left(N u_{x}\right)$ and $\left(S h_{x}\right)$ are increased when Prandtl number $(P r)$ and Brownian motion are increases. $\left(S h_{x}\right)$ increased when Brownian motion $N b$ increases and decreased when Prandtl number $(\mathrm{Pr})$ is increases.

The effect of Lewis Number $(L e)$ and Thermophoresis parameter $(N t)$ on $\left(\tau_{X}\right),\left(N u_{x}\right)$ and $\left(S h_{x}\right)$ at various point along the surface $\mathrm{x}(0,0.5,1.0)$ for the Cone and Plate are shown in Tables 6 and 7 respectively. $\tau_{X}, N u_{x}$ and $S h_{x}$ are increased over the surfaces from their stagnation point $\mathrm{x}=0$ through 0.5 to 1.0 . Also observed that Skin friction, Nusselt and 


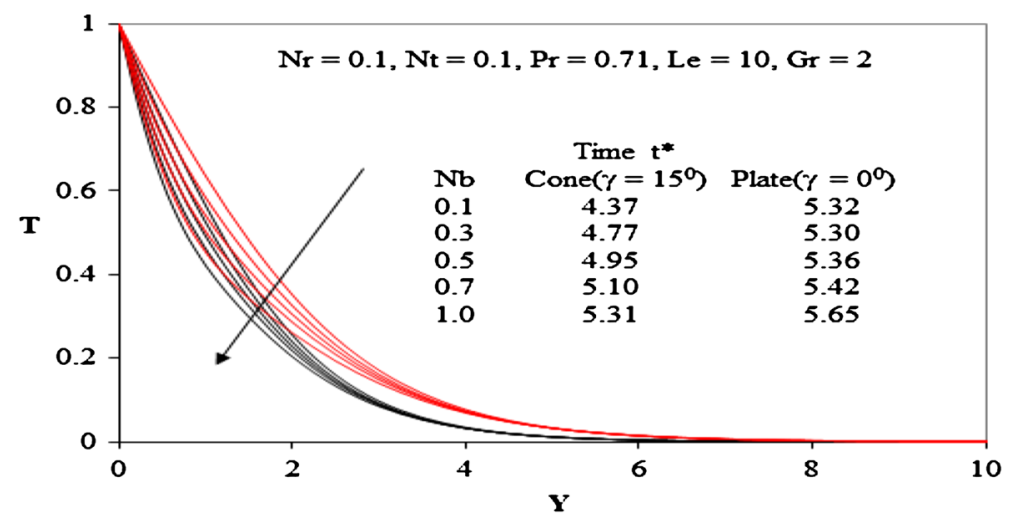

Fig. 5 Steady state temperature profiles at $\mathrm{X}=1.0$ for different $N b$ over cone and plate

Fig. 6 Steady state nanoparticle concentration profiles at $\mathrm{X}=1.0$ for different $\mathrm{Nr}$ over cone and plate

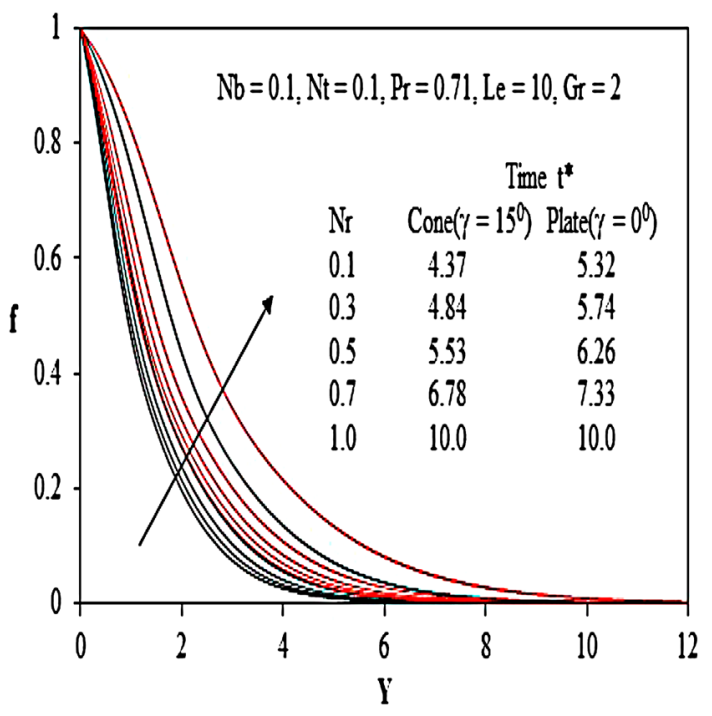

Sherwood number values decreased when both thermophoresis parameter $(N t)$ and Lewis Number $(L e)$ increases.

Table 8 shown the effect of cone apex angle $\gamma$ and of Buoyancy ratio parameter $\mathrm{Nr}$ on $\left(\tau_{X}\right),\left(N u_{x}\right)$ and $\left(S h_{x}\right)$ at various point along the surface (i.e. $\left.\mathrm{x}=0,0.5,1.0\right)$ over Cone. Skin fraction number $\left(\tau_{X}\right)$ is increased over the cone surface, also the same trend observed for Nusselt and Sherwood number. $\tau_{X}, N u_{x}$ and $S h_{x}$ values decreased when both buoyancy ratio parameter $\mathrm{Nr}$ and angle $\gamma$ increases.

The Figs. 3, 4, and 5 are represents the effect of Brownian motion $N b$ (appears in Eq.(14) on the longitutudinal nanoparticles volume fraction, velocty, temperature respectively. Brownian motion states the flow in the nanofluid boundary layer. Brownian diffusion promotes heat conduction. The nanoparticles increases the surface area for heat transfer. Nanofluid is a two phase fluid where the nanoparticles move randomly and increase he energy exchange rates. Brownian motion reduces nanoparticle diffusion. It is seen that the Brownian motion $\mathrm{Nb}$ increases, nanoparticle volume fraction, velocity, and temperature all are decreased. 
Fig. 7 Steady state velocty profiles at $\mathrm{X}=1.0$ for different $\mathrm{Nr}$ over cone and plate

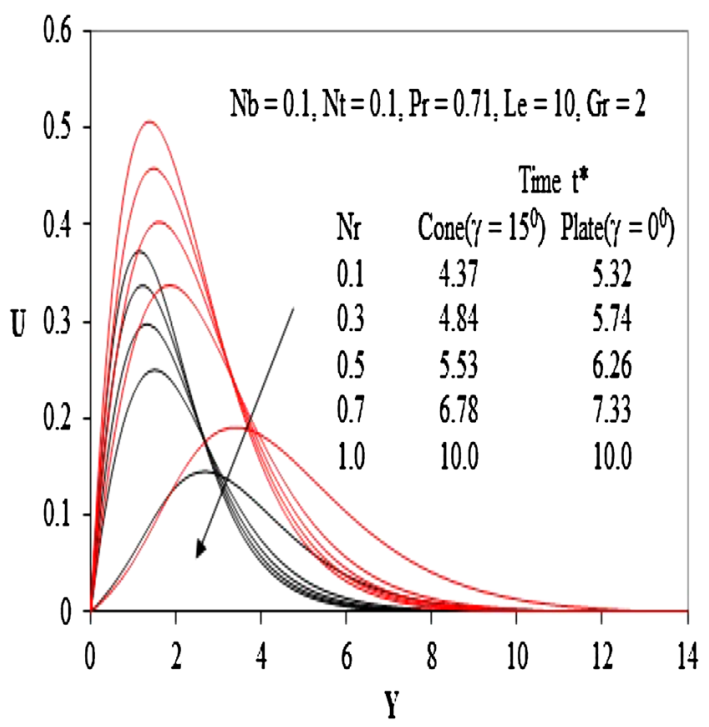

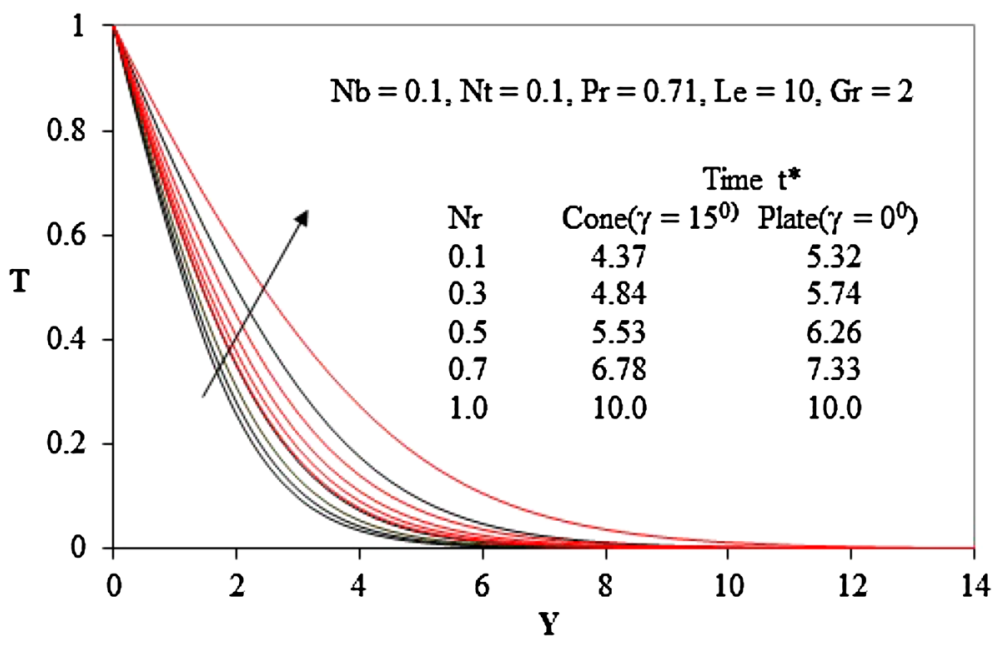

Fig. 8 Steady state temperature profiles at $\mathrm{X}=1.0$ for different $\mathrm{Nr}$ over cone and plate

The Figs. 6, 7, and 8 depicts the effect of the buoyancy ratio parameter $\mathrm{Nr}$ on the longitutudinal nanoparticles volume fraction, velocty, temperature respectively. The parameter $\mathrm{Nr}$ appears only in the momentum boundary layer Eq. (13). Buoyancy is principally a macroscale effect. The buoyancy influences the velocity and temperature fields, however, has a minor effect on nano particle diffusion. This explains the minor influence ofbuoyancy on concentration profiles. It is seen the Buoyancy ratio parameter $\mathrm{Nr}$ increases, nanoparticle volume fraction and temperature increasing while velocity is decreased.

The effect of the thermophoresis parameter $N t$ on the longitutudinal nanoparticles volume fraction, velocty, temperature shown in Figs. 9, 10, and 11. Thermophoresis parameter, $\mathrm{Nt}$ appears in the thermal and concentration boundary layerequations. As we note that, it is coupled with temperature function and plays a vital role inshaping the diffusion of heat 
Fig. 9 Steady state nanoparticle concentration profiles at $\mathrm{X}=1.0$ for different $N t$ over cone and plate

Fig. 10 Steady state velocty profiles at $\mathrm{X}=1.0$ for different $N t$ over cone and plate
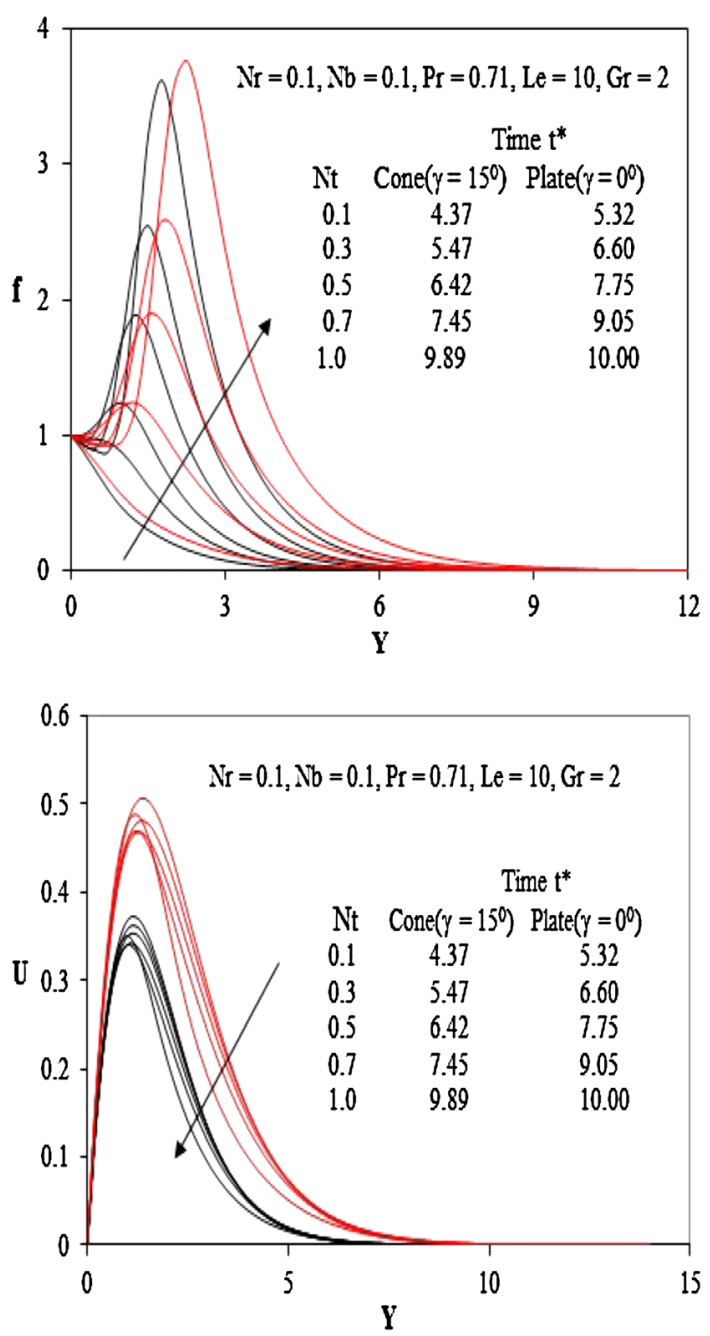

and nanoparticle concentartion in the regime. It is seen that the Thermophoresis parameter $N t$ increases, nanoparticle volume fraction and temperature are increased but velocity is decreased.

The Figs. 12, 13, and 14 shown the effect of $\operatorname{Gamma}(\gamma)$, the cone apex half angle on the longitutudinal nanoparticles volume fraction, velocty, temperature respectively. It is seen that the Gamma $\gamma$ increased, nanoparticle volume fraction and temperature are increased while velocity is decreased.

The effect of the Lewis number $L e$ on the longitutudinal nanoparticles volume fraction, velocty, temperature respectively depicts by Figs. 15, 16, and 17. It is seen that the Lewis number $L e$ increases then nanoparticle volume fraction is decreased while velocity and temperature are increased.

Figures 18, 19, and 20 illustrate the effect of the Prandtl number $\operatorname{Pr}$ on the longitutudinal nanoparticles volume fraction, velocty, temperature respectively. Prandtl number signifies the ratio of viscous diffusion to thermal diffusion in the boundary layer regime. With greater $\mathrm{Pr}$ 


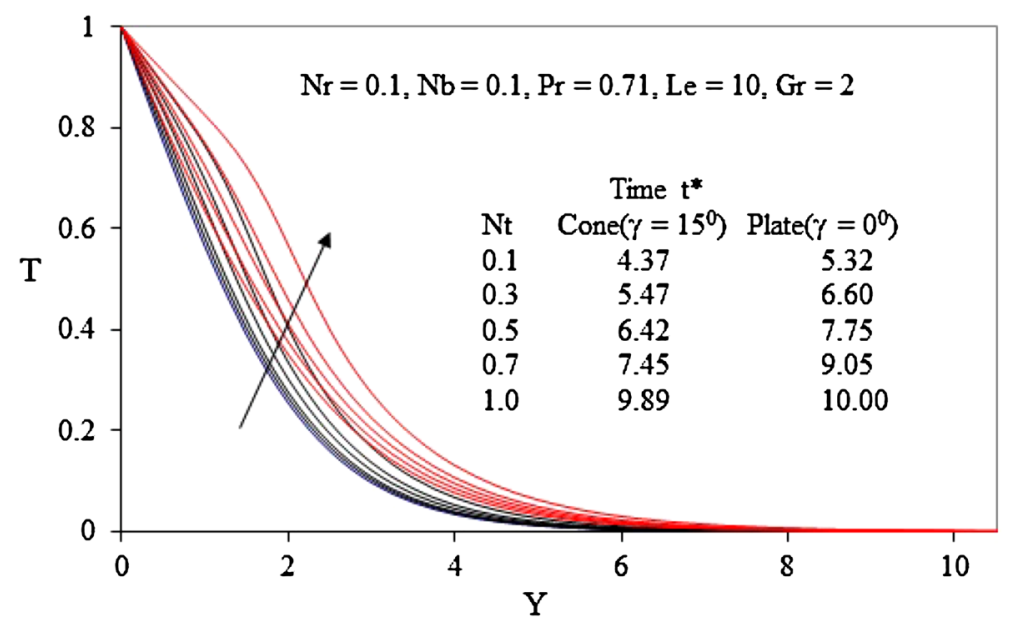

Fig. 11 Steady state temperature profiles at $\mathrm{X}=1.0$ for different $N t$ over cone and plate

Fig. 12 Steady state

nanoparticle concentration profiles at $\mathrm{X}=1.0$ for different $\gamma$ over cone and plate

Fig. 13 Steady state velocty profiles at $\mathrm{X}=1.0$ for different $\gamma$ over cone and plate
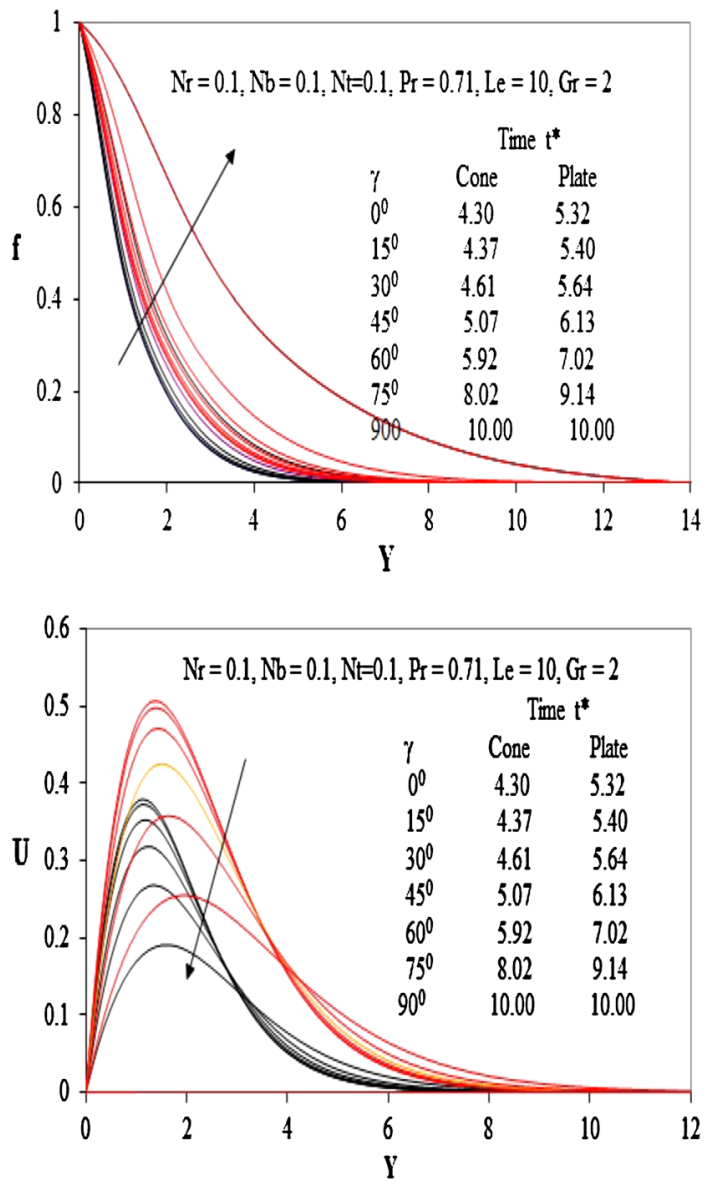


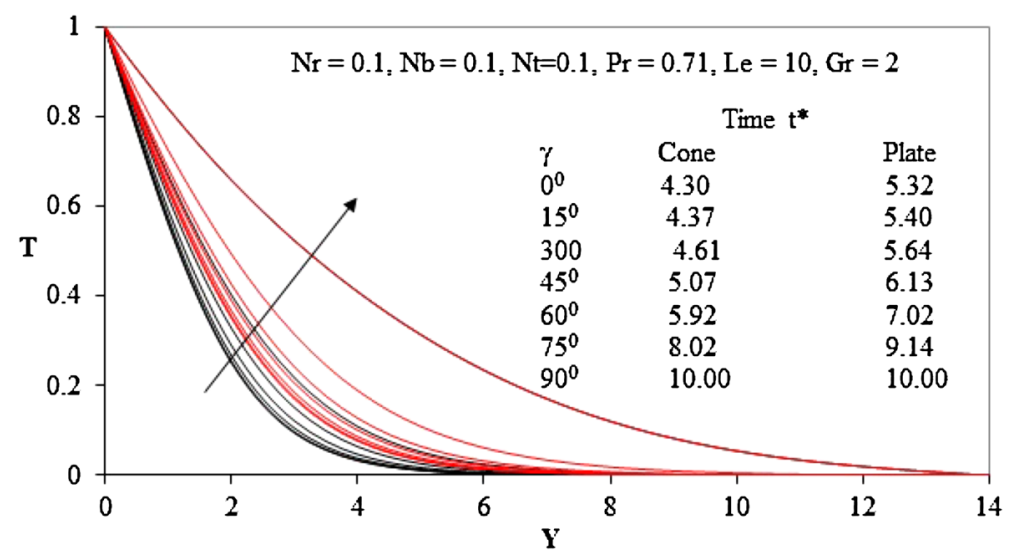

Fig. 14 Steady state temperature profiles at $X=1.0$ for different $\gamma$ over cone and plate

Fig. 15 Steady state nanoparticle concentration profiles at $\mathrm{X}=1.0$ for different Le over cone and plate

Fig. 16 Steady state velocty profiles at $\mathrm{X}=1.0$ for different Le over cone and plate
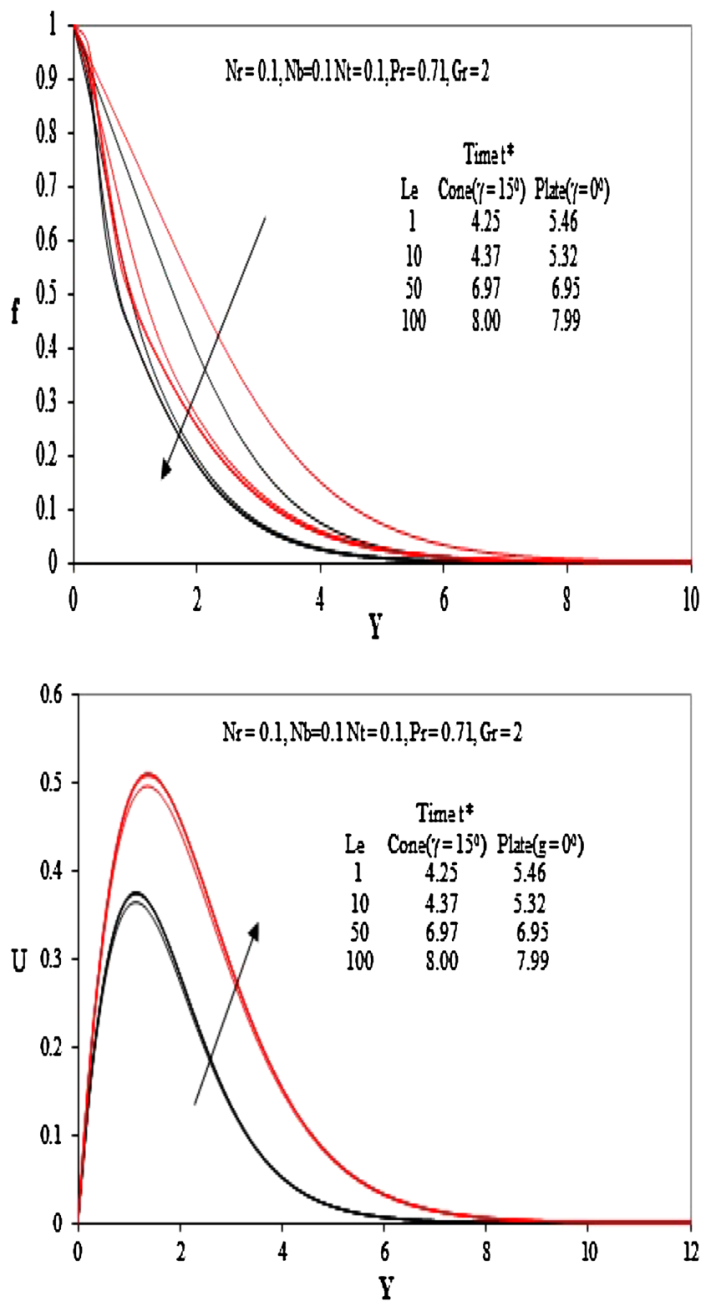


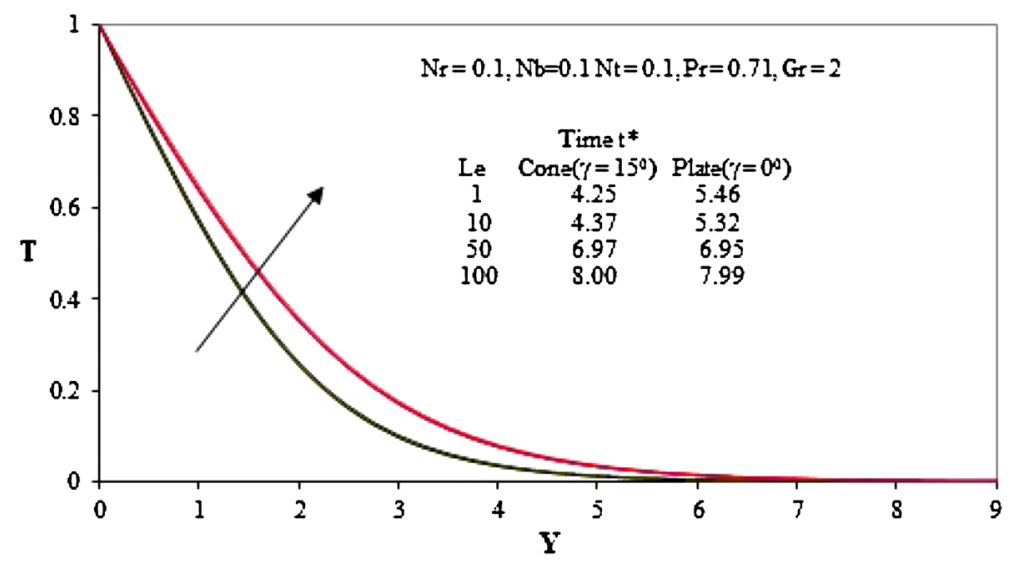

Fig. 17 Steady state temperature profiles at $\mathrm{X}=1.0$ for different Le over cone and plate

Fig. 18 Steady state nanoparticle concentration profiles at $\mathrm{X}=1.0$ for different Pr over cone and plate

Fig. 19 Steady state velocty profiles at $\mathrm{X}=1.0$ for different Pr over cone and plate
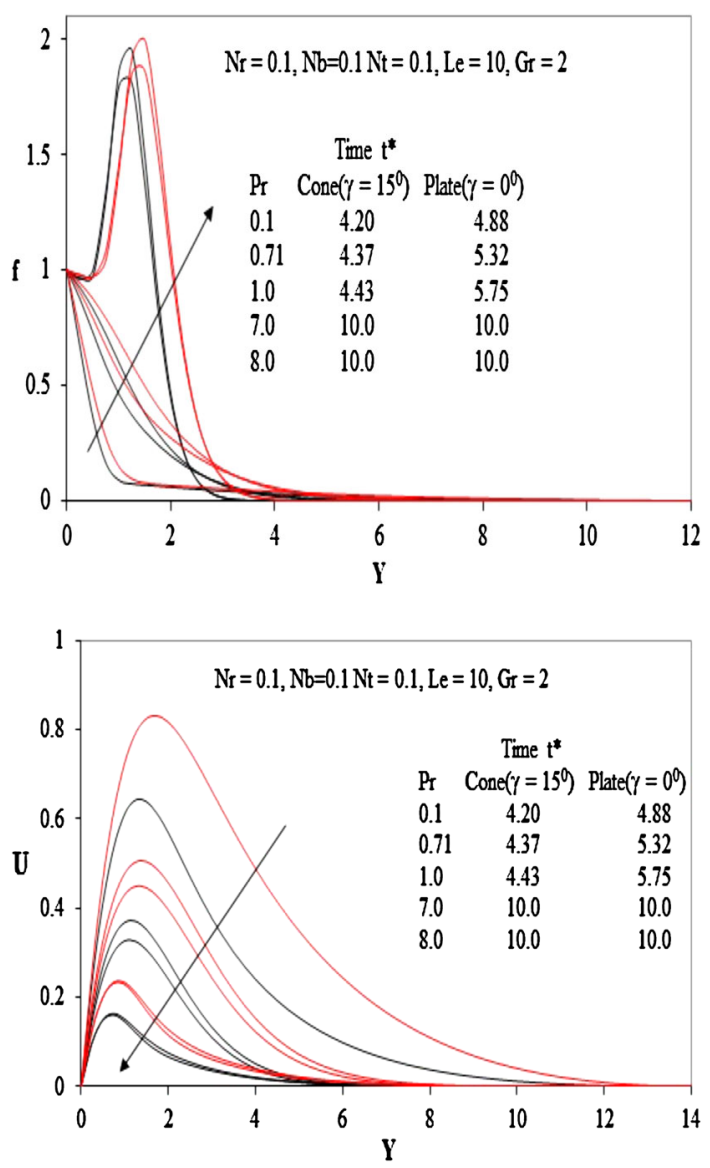


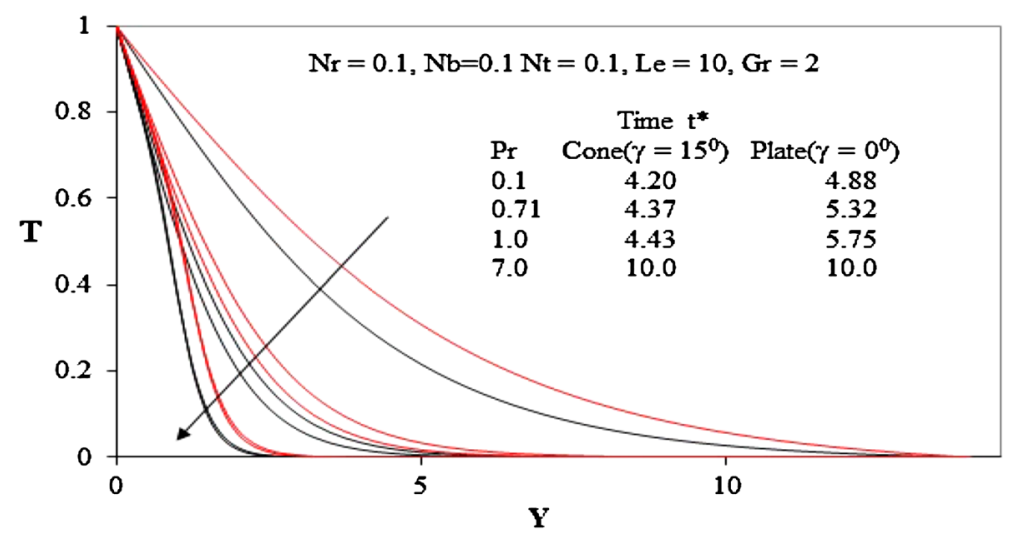

Fig. 20 Steady state temperature profiles at $X=1.0$ for different Pr over cone and plate

Fig. 21 The local skin friction profiles for different $\mathrm{Nb}$ at the steady state case for $\gamma=15^{\circ}$
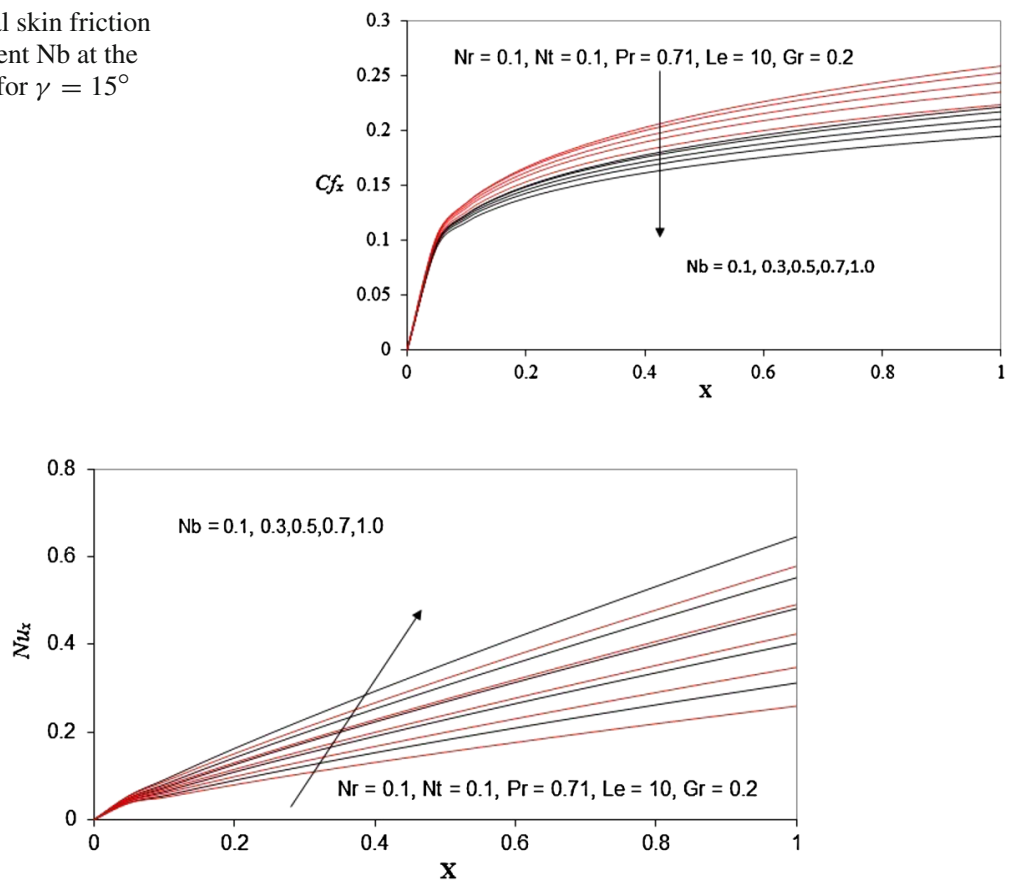

Fig. 22 The local heat transfer rate (Nusselt number) profiles for different $\mathrm{Nb}$ at the steady state case for $\gamma=15^{\circ}$

values, viscous diffusion rate exceeds thermal diffusion rate. It is seen that the Prandtl number $\mathrm{Pr}$ increases, nanoparticle volume fraction is increased while velocity and temperature are decreased.

Figures 21, 22, and 23 depict the distributions of friction factor $\tau_{X}$, Heat transfer coefficient $\mathrm{Nu}_{\mathrm{x}}$ and Nano particle volume fraction rate of coefficient $\mathrm{Sh}_{\mathrm{x}}$ respectively with Brownian motion $N b$. It is seen that the Brownian motion $N b$ increases, Skin fraction number is decreased while Sherwood number and Nusselt number are increased. 
Fig. 23 The local mass transfer rate (Sherwood number) profiles for different $\mathrm{Nb}$ at the steady state case for $\gamma=15^{\circ}$

Fig. 24 The local skin friction profiles for different $\mathrm{Nr}$ at the steady state case for $\gamma=15^{\circ}$

Fig. 25 The local heat transfer rate (Nusselt number) profiles for different $\mathrm{Nr}$ at the steady state case for $\gamma=15^{\circ}$

Fig. 26 The local mass transfer rate (Sherwood number) profiles for different $\mathrm{Nr}$ at the steady state case for $\gamma=15^{\circ}$
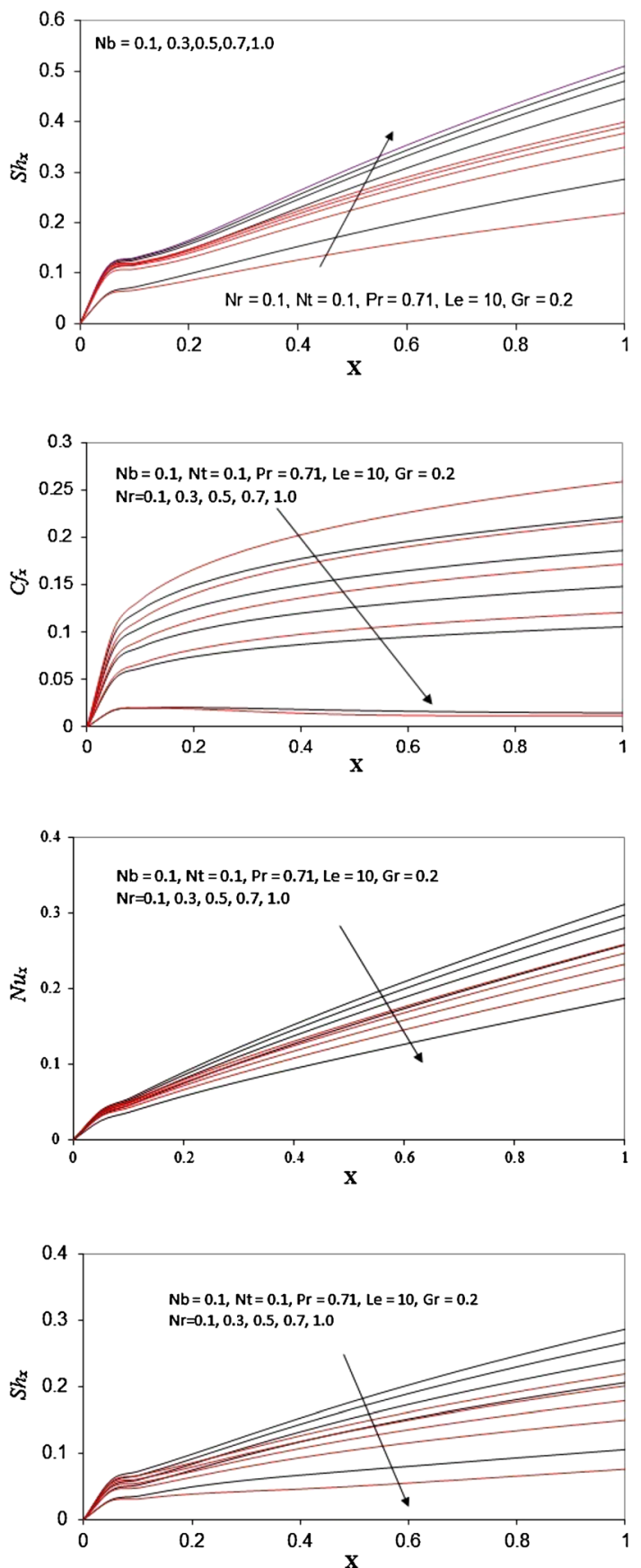

The effect of Buoyancy ratio parameter $N r$ on $\tau_{X}, N u_{x}$ and $S h_{x}$ respectively illustrates the Figs. 24, 25, and 26. It is seen that the $N r$ increases, Skin fraction number, Nusselt number and Sherwood number are decreased. 


\section{Conclusions}

In the present work, we studied theoretically the problem of unsteady natural convection flow of a nanofluid over a permeable vertical cone or plate subjected to constant heat and nanoparticles volume fraction. The model used for the nanofluid incorporates the effects of Brownian motion and thermophoresis. The obtained non-dimensional equations were solved numerically by an efficient implicit finite-difference method with stability and convergence analysis also has been employed as a solution technique to complete the formulation of the unsteady model. The results focused on the effects of the buoyancy ratio, Brownian motion parameter, thermophoresis parameter, Prandtl number and Lewis number for different thermophysical parameters on the local Nusselt and Sherwood numbers. It was found that the buoyancy ratio was increased, both the local Nusselt and Sherwood numbers decreased. In addition, it was concluded that as the Brownian motion parameter increased, the local skin friction decreased while the local Nusselt number and local Sherwood number increased. However, they both decreased as the thermophoresis parameter increased. In addition, increasing the Lewis number produced increases in both of the local skin friction, the local Nusselt and Sherwood numbers.

The results are presented for the effect of various parameters. The velocity, temperature, and concentration effects on the sheet are studied and shown graphically. From the present study, the concluding remarks have been taken as follows:

(1) The time taken to reach steady state increases with increasing $\gamma, \mathrm{Nr}, \mathrm{Nb}, \mathrm{Nt}$.

(2) The velocity reduces when the parameters $\gamma, \mathrm{Nr}, \mathrm{Nb}, \mathrm{Nt}$ are increased.

(3) Larger values of the Lewis number showed a significant effect on momentum boundary layer.

(4) The influence of g over the local skin friction $\tau_{X}$, local Nusselt number Nux local Sherwood number Shx are less near the vertex of the cone and then increases slowly with increasing distance from the vertex.

(5) The effect of the Brownian motion and thermophoresis stabilizes the boundary layer growth.

(6) The boundary layers are highly influenced by the Prandtl number and the thermal boundary layer thickness increases as a result of increasing Prandtl number.

(7) The presence of heavier species (large Lewis number) decreases the concentration in the boundary layer.

Acknowledgments The authors are grateful to reviewers for their constructive comments which have helped to improve the present article.

\section{References}

1. Maxwell, J.C.: Atreatise on Electricity and Magnetism, 2nd edn. Clarendon Press, Oxford (1981)

2. Choi, S.U.S.: Enhancing thermal conductivity of fluids with nanoparticles. In: Siginer, D.A., Wang, H.P. (eds.) Development and Applications of Non-Newtonian Flows, pp. 99-105. ASME, New York (1995). FED-vol. 231/MD-vol. 66

3. Buongiorno, J.: Convective transport in nanofluids. ASME J. Heat Transf. 128, 240-250 (2006)

4. Kuznetsov, A.V., Nield, D.A.: Thermal instability in a porous medium layer saturated by a nanofluid: Brinkman model. Transp. Porous Media 81, 409-422 (2010)

5. Godson, L.B., Raja, D., Mohan Lal, D., Wongwisesc, S.: Enhancement of heat transfer using nanofluids: an overview. Renew. Sustain. Energy Rev. 14, 629-641 (2010) 
6. Chamkha, A.J., Gorla, R.S.R., Ghodeswar, K.: Non-similar solution for natural convective boundary layer flow over a sphere embedded in a porous medium saturated with a nanofluid. Transp. Porous Media 86, 13-22 (2011)

7. Bapuji, P., Chamkha, A.J., Pop, I.: Unsteady laminar free convection flow past a non-isothermal vertical cone in the presence of a magnetic field. Chem. Eng. Commun. 199, 354-367 (2012)

8. Gorla, R.S.R., Chamkha, A.J., Hossain, A.: Mixed convection flow of non-newtonian fluid from a slotted vertical surface with uniform surface heat flux. Can. J. Chem. Eng. 87, 534-540 (2009)

9. Chamkha, A.J., Rashad, A.M., Aly, A.: Transient natural convection flow of a nanofluid over a vertical cylinder. Meccanica 48, 71-81 (2013)

10. RamReddy, Ch., Murthy, P.V.S.N., Chamkha, Ali J., Rashad, A.M.: Soret effect on mixed convection flow in a nanofluid under convective boundary condition. Int. J. Heat Mass Transf. 64, 384-392 (2013)

11. Balla, C.S., Naikoti, K.: Finite element analysis of magnetohydrodynamic transient free convection flow of nanofluid over a vertical cone with thermal radiation. In: Proceedings of the Institution of Mechanical Engineers, Part N: Journal of Nanoengineering and Nanosystems (2014). doi:10.1740349914552879

12. Motsa S. S., Awad F. G., and Khumalo M., Nonlinear nanofluid flow over heated vertical surface with sinusoidal wall temperature variations, abstract and applied analysis, 2014 (2014), Article ID 408230

13. Pop, I., Ingham, B.D.: Convective Heat Transfer: Mathematical and Computational Modelling of Viscous Fluids and Porous Media. Pergamon, Oxford (2001)

14. Incropera, F.P., Dewitt, D.P.: Fundamentals of Heat and Mass Transfer, 5th edn. Wiley, New York (2007)

15. Das, S.K., Choi, S.U., Wenhua, Y., Pradeep, T.: Nanofluids: Science and Technology. Wiley, Hoboken (2008)

16. Minkowycz, W.J., Sparrow, E.M., Abraham, J.P.: Nanoparticle Heat Transfer and Fluid Flow (Advances in Numerical Heat Transfer: Computational and Physical Processes in Mechanics and Thermal Sciences), vol. 4. CRC Press, Taylor \& Francis Group, Boca Raton (2013)

17. Chamkha, A.J.: Coupled heat and mass transfer by natural convection about a truncated cone in the presence of magnetic field and radiation effects. Numer. Heat Transf. A 39(5), 511-530 (2001)

18. Rushi Kumar, B., Sivaraj, R.: MHD Viscoelastic fluid non-Darcy flow over a vertical cone and a plate. Int. Commun. Heat Mass Transf. 40, 1-6 (2013)

19. Crank, J., Nicolson, P.: A practical method for numerical evaluation of solutions of partial differential equations of the heat conduction type. Proc. Camb. Phil. Soc. 43, 50-67 (1947)

20. Vasu, B., Prasad, V.R.: Radiation and mass transfer effects on transient free convection flow of a dissipative fluid past semi-infinite vertical plate with uniform heat and mass flux. J. Appl. Fluid Mech. 4(1), 15-26 (2011)

21. Prasad, V.R., Bhaskar Reddy, N., Muthucumaraswamy, R.: Radiation and mass transfer effects on twodimensional flow past an impulsively started infinite vertical plate. Int. J. Therm. Sci. 46(12), 1251-1258 (2007) 